\title{
Analysis of Manufacturing Cooperation among BRICS Member States Based on Value Added Trade
}

\author{
Siqing. Hao \\ Econimics School of Shanghai University \\ SHU \\ Shanghai, China \\ Siqing_shu@163.com
}

\begin{abstract}
By means of Trade in Value Added Database (TIVA), this paper measures the global value chain participation and position index of the manufacturing industry in BRICS countries and compares it with the developed countries to assess the depth of the BRICS manufacturing industries embedded in the global value chain. According to the European Union's World Input-Output Database (WIOD), the foreign value-added ratio in final output of the BRICS countries and the evolution of its internal cooperation are measured. In the end, the following conclusions are drawn: (1) Except for Brazil, other BRICS countries have lower status in the global value chain; (2) Although the foreign value added from the member countries in the manufacturing industry is low, internal cooperation is closer than ever; (3) Manufacturing links between India and Brazil are closer than those of other member states.
\end{abstract}

Keywords-BRICS; Manufacturing industry; Global value chain; Value added trade cooperation

\section{INTRODUCTION}

Along with the development of the global value chain, more and more countries have exerted their comparative advantages by participating in the global value chain. Among them, emerging economies are considered to be the most profitable, and the BRICS countries are representative. Emerging countries have received extensive attention from the worldwide: Some scholars believe that the BRICS countries still have a lot of room for cooperation in the future, while some scholars have pointed out that the BRICS countries are politically "dissociated" and the cooperation between member states is not substantive. As a cornerstone of a country's economy, manufacturing industry has a great impact on the depth of a country's embedded global value chain. Therefore, in this paper, the author will examine the evolutionary trend of value-added trade cooperation among BRICS countries in manufacturing industry over the past 15 years.

\section{LITERATURE REVIEW}

With the steady improvement of its economic strength, the BRICS countries are increasingly ranked in the world economy and are highly expected. With regard to strategic conflicts and coordination of interests among BRICS countries, the academic community has conducted in-depth research and exploration from many fields. At present, the quantitative analysis of trade cooperation among BRICS countries is mainly based on the perspective of total value trade. However, in the era of globalization of processing trade and intermediate trade, the value added accounting method can break through the country boundary of production and sales. The different production links of the same product and the added value will be attribute to different countries and regions, which is closer to the "truth of trade".

The study on value added trade began with Hummels et.al (2001). While proposing the value-added trade theory, he also gave a method for measuring the direct and indirect added value contained in a country's export (HIY method). Since then, the academic community has carried out a number of studies related to value-added trade. Until 2010, Koopman et. al (2010) proposed KPWW added value accounting method, which can make up for deficiencies of Hummels et.al (2001) "same-scale assumptions" and "imports 100\% from foreign ". Based on Koopman (2010), Fally (2011) proposed a method to measure the position and participation of a country in the global value chain. Zhi Wang, Shangjin Wei et. al (2017, a) combines world input-output data and national economic accounts, dividing the production activities involved in a country into activities that participate in the global value chain and not participate in the global value chain. Which have improved the method of measuring the participation and position index of a country in the global value chain.

\section{RESEARCH METHODS AND DATA DESCRIPTION}

\section{A. Research Methods}

Methord of measuring participation and position in global value chain

In measuring the participation and position index of manufacturing in the global value chain

in different countries, this paper draws on the methord of Fally (2011):

$$
\begin{gathered}
G V C_{S} 1 B=100 \times \frac{F V_{s}}{E X_{S}} \\
G V C_{s} 1 \mathrm{~F}=100 \times \frac{I V_{s}}{E X_{r}} \\
G V C_{s} 2=100 \times\left[\ln \left(1+\frac{I V_{S}}{E X_{r}}\right)-\ln \left(1+\frac{F V_{s}}{E X_{S}}\right)\right]
\end{gathered}
$$

Formula (1) measures the backward participation of $\mathrm{S}$ manufacturing industry in GVC, which

reflects the use of foreign intermediate products in a country's final products. Formula (2) measures the forward 
participation of $\mathrm{S}$ manufacturing industry in GVC, reflecting a country's ability to provide intermediate products to other countries' export. The comprehensive of formulas (1) and (2) can be used to derive the GVC position index of a country's manufacturing industry as shown in formula (3). Where $E V_{s}$ indicates the total value of a country's exports, $F V_{s}$ indicates the value added from foreign countries in the $S$ country's exports, and $I V_{s}$ indicates the indirect export of country $S$ through the importing country $r$.

Method of measuring the proportion of value added from BRICS countrie

In accounting for the value added of the BRICS manufacturing industry from foreign and

member states, the methods of Los, Timmer and de Vries (2014) are used. Defining VA(i,j) as the intermediate input that country (region) $\mathrm{j}$ provide to product $\mathrm{i}$. Then the value of the final product in country $\mathrm{S}$ is $\operatorname{FINO}(\mathrm{i}, \mathrm{s})$ :

$$
\mathrm{FINO}_{\mathrm{i}, \mathrm{s}}=\sum_{\mathrm{j}=1}^{\mathrm{s}} \mathrm{VA}_{\mathrm{i}, \mathrm{j}}
$$

Then we get the value added from foreign countries $\mathrm{FVA}_{\mathrm{i}, \mathrm{j}}$ by minus the value added provided by country $\mathrm{S}$ :

$$
\mathrm{FVA}_{\mathrm{i}, \mathrm{j}}=\sum_{\mathrm{j}=1}^{\mathrm{s}-1} \mathrm{VA}_{\mathrm{i}, \mathrm{j}}=\mathrm{FINO}_{\mathrm{i}, \mathrm{j}}-\mathrm{VA}_{\mathrm{i}, \mathrm{j}}
$$

Devided the formula (5) by formulam (4) to get the proportion of value added from foreign countries:

$$
\mathrm{FVAS}_{i, j}=\frac{\mathrm{FVA}_{\mathrm{i}, \mathrm{j}}}{\mathrm{FINO}_{i, j}}
$$

When the value added from abroad in a country's manufacturing industry is divided into the value added from the BRICS countries and beside the BRICS countries, formula (7) and formula (8) are used to calculate the value added from BRICS countries and its proportion:

$$
\begin{array}{r}
\mathrm{BFVA}_{\mathrm{i}, \mathrm{j}}=\sum_{\mathrm{k} \in \mathrm{BRICS} \mathrm{VA}_{\mathrm{i}, \mathrm{k}}-\mathrm{VA}_{\mathrm{i}, \mathrm{s}}} \\
\mathrm{BFVAS}_{\mathrm{i}, \mathrm{j}}=\frac{\mathrm{BFVA}_{\mathrm{i}, \mathrm{j}}}{\mathrm{FINO}_{\mathrm{i}, \mathrm{j}}}
\end{array}
$$

\section{B. Data Sources and Description}

In the measurement of GVC participation and position index, we use the TIVA database jointly released by WTO and OECD. The WIOD database issued by the European Union was adopted when measuring the growth trend of manufacturing value added trade and the internal value added structure among BRICS countries.

\section{Research Framework}

There is a large amount of intermediate goods trade in the global value chain division of labor. The value of export products comes from different countries. The value added trade measurement method can trace the source countries and industries of the value added. The research, measurement and analysis of this paper are based on the value added accounting method. Follow the framework below:

1. The depth of the BRICS manufacturing participating in the global value chain. Using data from the TIVA database to measure the global value chain participation and position index of BRICS and developed countries, to analyze the development of BRICS manufacturing in a global framework.

2. Internal circulation analysis of manufacturing inside the BRICS countries. Using the WIOD database to measure the proportion of foreign value added and member states, to analyze its scale and development trend.

\section{The DePth OF THE BRICS MANUfACtURING EMBEDDED IN THE GLOBAL VALUE CHAIN}

\section{A. Analysis of the forward and backward participation index of BRICS countries in the global value chain}

First, we will examine the overall development of BRICS manufacturing from the framework of global manufacturing. Outside China, India, Russia, Brazil and South Africa, joining the developed countries such as the United States, Germany and Japan, comprehensively and objectively evaluate the development of the manufacturing industry in the BRICS countries. In the first part, the front and back participation indicators are used to compare the heterogeneity of the BRICS countries and developed countries in the manufacturing industry. Figures 1 and figures 2 show the forward and backward participation index of the above-mentioned eight countries' manufacturing industries in the global value chain:

Backward GVC participation refers to the proportion of a country's use of intermediates produced by other countries to produce export products, while forward GVC participation refers to the intermediate products provided by a country for imports of other countries. From the relative size of backward GVC participation index and forward GVC participation index, the US, Japan, and Germany share the similar structures, and the forward participation is higher than the backward participation. Therefore, in the global value chain of manufacturing, the ability for the developed countries to provide intermediate products to other countries is greater than the ability to absorb intermediate products produced by other countries, they are in a state of net outflow of intermediate products. However, from the perspective of development trends, the GVC backward participation index of manufacturing in developed countries has an upward trend, and the forward participation index has a downward trend. The ability of these three countries to create added value will decline in the future.

In the BRICS countries, the GVC participation of Chinese manufacturing industry has different characteristics from other countries. It is not only different from the developed countries, but also different from the other BRICS countries. Judging from the relative size of forward and backward participation, other BRICS countries besides China, have also shown similarities with developed countries such as the United States. However, from the perspective of growth trends, except for India, the growth trend of participation in other BRICS countries is opposite to that of developed countries. The backward participation is declining and the forward participation is on the rise. 


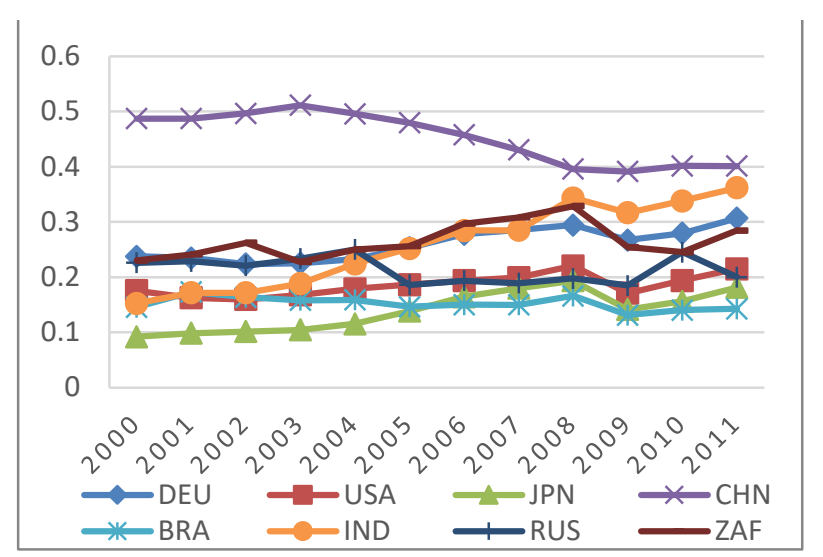

Fig. 1 The Backward Participation Index of Different Countries from 2000 to 2011

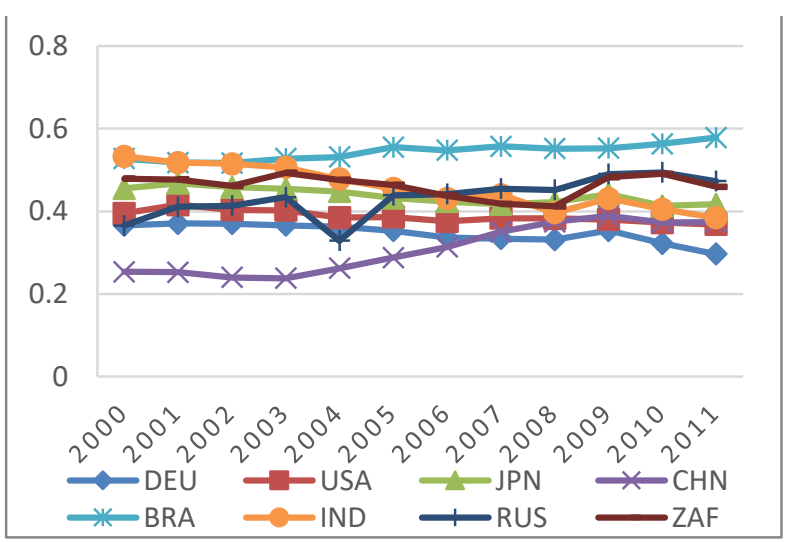

Fig. 2 The Forward Participation Index of Different Countries from 2000 to 2011

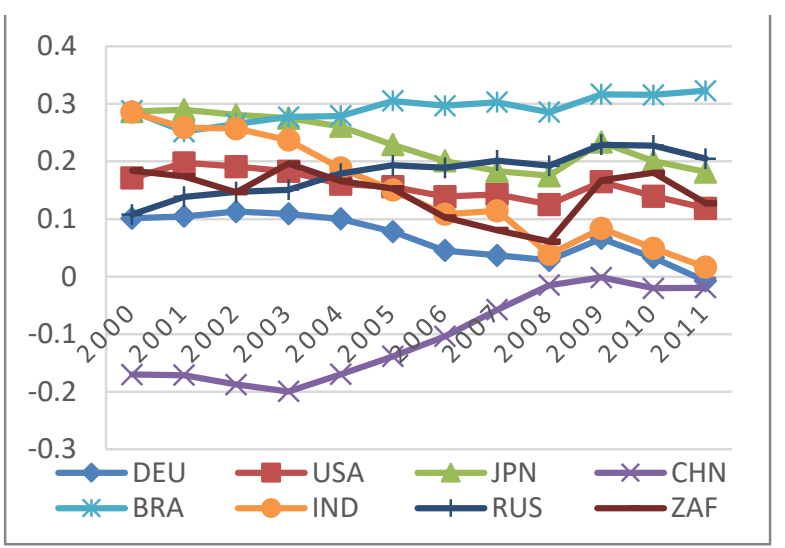

Fig. 3 The GVC position Index of Different Countries from 2000 to 2011

\section{B. Analysis of the position in global value chain of BRICS countries}

According to the above analysis, the GVC position index of these countries can be obtained. Generally, position index is positively indicating that a country's manufacturing industry is in the upstream of the global value chain, and a negative index means that a country is in the downstream of the global value chain. Figure 3 shows the GVC position indicators of different countries.

According to the data in the TIVA database, only China in the BRICS countries is in the downstream of the manufacturing global value chain. This is related to the characteristics of China's manufacturing processing trade. In the global division of labor in manufacturing, China has mainly completed low value-added links such as processing and assembly.

In all countries, the GVC position index of Brazilian manufacturing has surpassed that of developed countries. This is because Brazil mainly exports natural resource-intensive products such as iron ore, oil, soybeans and coffee. Russia also exhibits similar characteristics. Russia mainly exports natural resources as oil and natural gas, while imported products are mainly manufactured goods, so both countries are in a state of net outflow of intermediate goods. In comparison, the GVC position index of the Brazilian manufacturing industry is higher than that of Russia, mainly due to the higher level of development of the producer service industry in Brazil, the better producer service industry can be well embedded in the manufacturing industry and provides opportunity to the development of manufacturing industries.

The United States, Japan, and Germany are all in the upstream of the global value chain. Germany's position is lower than that of other BRICS countries except to China, mainly because Germany has outsourced some intermediate production to other Eastern European countries in recent years.

\section{ANALysis OF the VAlUE AdDED TRAdE COOPERATION IN THE MANUFACTURING INDUSTRY OF THE BRICS COUNTRIES}

As Brazil, China, India and Russia, which represent emerging market investment countries, whether their trade become more closely linked by the concept of "BRIC countries", the following research about the trade cooperation of BRICS countries will focus on the foreign value added embeded in the final output, the value added from the member states and the ratio of them. Meanwhile compare the structure of the value added from member states.

Compared with the proportion of foreign value-added, the proportion of value added from member countries is relatively small. Among them, India absorbs the highest proportion of internal value added from member countries, followed by Russia, while China absorbs the smallest proportion of value added from member states among the four countries, which is because China's division of labor is mainly linked with developed countries such as Europe and the United States. However, in any country, the ratio of the added value from the member countries to the proportion of their foreign value added is on the rise. The upward trend of Brazil and Russia is obvious. Although China and India show a certain range of fluctuations, the overall is still showing an upward trend. 

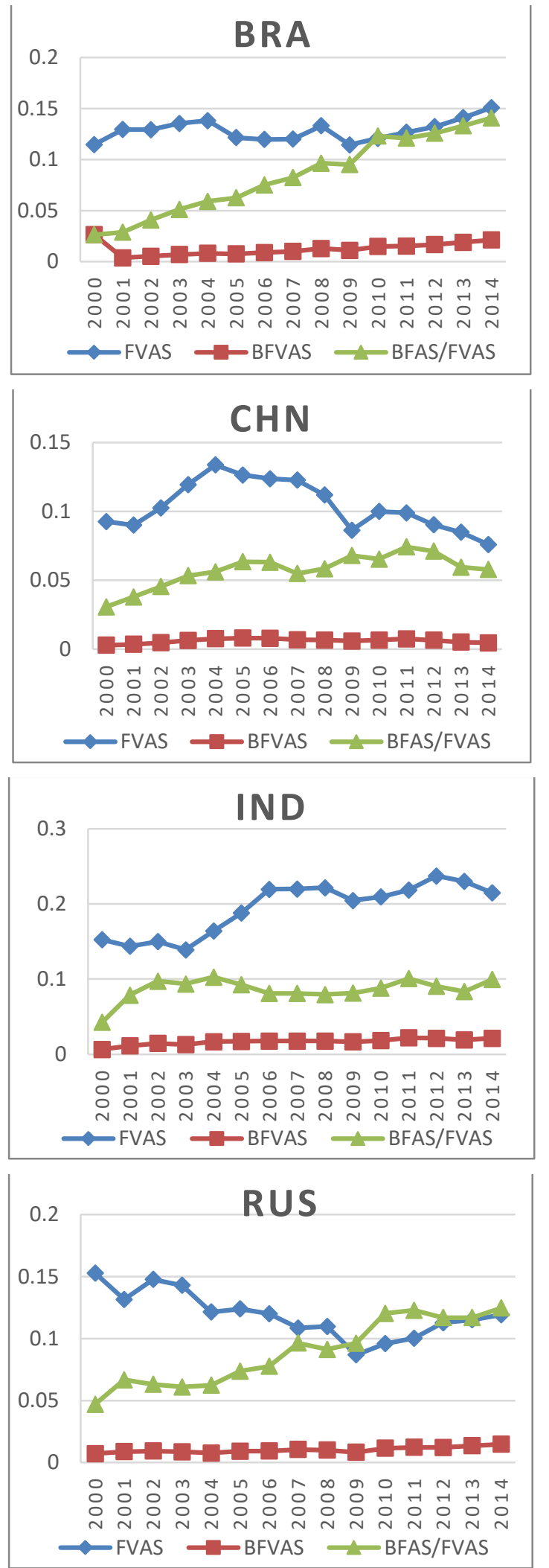

Fig. 4 Foreign value-added rate of BRICS countries, internal value-added rate and relative proportion of member states, analysis of the structure of value-added contributions inside the member countries from 2000 to 2014
When measured by the proportion of value added from member countries, the BRICS cooperation in manufacturing is closer than past. Judging from the proportion of the value added from member countries included in the final output, India is the highest in 2014, followed by Russia, Brazil and China is the least. However, China's added value export to other member states accounted for the largest, India and Russia absorbed more manufacturing value added from China, while Brazil absorbed more value added from India. Throughout the cooperation between India and the other three BRICS countries, its connection with Brazil is relatively close and the degree of closeness is increasing. However, the contribution to the value-added of China and Russia is relatively low, mainly due to the electronics of India is more developed and more manufacturing value added are exported to Europe and the United States, which is similar to China; but from the closeness of cooperation with other member states, India's performance is not great as China.

\section{CONCLUSIONS}

This paper assesses the position and participation of BRICS manufacturing in the global value chain and the value-added trade cooperation of the member states through the EU World Input-Output Table and the Trade in Value Added Database, and draws the following conclusions: (1) Except Brazil, other BRICS countries have lower positions in the global value chain; (2) Although the value added from member states in the manufacturing industry is still low but its rising trend is obvious, so the cooperation in manufacturing industries among BRICS countries is closer than before; (3) The manufacturing links between India and Brazil are closer than those of other member states.

\section{REFERENCES}

[1] Bouwmeester, M.C., J. Oosterhaven and J.M. Rueda-Cantuche, Measuring the EU vlue added embodied in EU foreign exports by consolidating 27 national supply and use tables For 2000-2007[R].No.14004-EEF:1-28

[2] Bart Los, Marcel P. Timmer, Gaaitzen J. de Vries. How global are global value chains? A new approach to measure international fragmentation [J]. Journal of regional science No. 0, 2014: 1-27

[3] Marcel P. Timmer, Bart Los, Robert Stehrer, Gaaitzen de Vries. Fragmentation, Incomes, and Jobs: An Analysis of European Competitiveness [J]. Policy research working paper 6833,2014(4).

[4] Koopman, R. , Zhi Wang, and Shang-Jin Wei. Tracing value-added and double counting in gross exports[J]. American Economic Review 2014, 104(2): 459-494

[5] Koopman ,R. ,William Powers, Zhi Wang, et al. Give Credit Where Is Due: Tracing Value Added In Global Productiong Chains[R]. National Bureau of Economic Research, 2010.

[6] Zhi Wang, Shang-Jin Wei, Xinding Yu, Kunfu Zhu. Measures of participation in global value chains and global business cycles[J].National Bureau of Economic Research working paper w23222,2017:5-9.

[7] Zhi Wang, Shang-Jin Wei, Xinding Yu, Kunfu Zhu. Characterizing global value chains: Production length and upstreamness[J] National Bureau of Economic Research working paper w23261,2017:7-20.

[8] Grubel, H. ,and E. Lloyd, Intra-industry trade :the theory and measursment of international trade in differentiated products, London: Macmillan. 